\title{
Differential needs of zinc in the CA3 area of dorsal hippocampus for the consolidation of contextual fear and spatial memories
}

\author{
Johnatan Ceccom, ${ }^{1,2}$ Emilie Bouhsira, ${ }^{1,2}$ Hélène Halley, ${ }^{1,2}$ Stéphanie Daumas, ${ }^{3}$ \\ and Jean Michel Lassalle ${ }^{1,2,4}$
}

${ }^{1}$ Université de Toulouse, UPS, Centre de Recherches sur la Cognition Animale, F-31062 Toulouse Cedex 9, France; ${ }^{2}$ CNRS, Centre de Recherches sur la Cognition Animale, F-31062 Toulouse Cedex 9, France; ${ }^{3}$ PMSNC, INSERM 952, CNRS UMR 7224, Université Pierre et Marie Curie, F-75005 Paris, France

\begin{abstract}
One peculiarity of the hippocampal CA3 mossy fiber terminals is the co-release of zinc and glutamate upon synaptic transmission. How these two players act on hippocampal-dependent memories is still unclear. To decipher their respective involvement in memory consolidation, a pharmacological approach was chosen. Using two hippocampal-dependent behavioral paradigms (water maze and contextual fear conditioning) we now report that glutamate at CA3 synapses is necessary and sufficient for the spatial learning consolidation process, whereas glutamate and zinc released by mossy fibers are both mandatory and exert cumulative effects on contextual fear consolidation, a form of learning with a strong emotional component.
\end{abstract}

The CA3 hippocampal area occupies a central position in the crossroads of multiple inputs. Besides, it possesses remarkable anatomical characteristics. Pyramidal cells have the peculiarity that they emit so-called recurrent collaterals interconnecting CA3 neurons, forming a real "auto-associative" network (Amaral and Witter 1995; Rolls 2007). Every CA3 neuron receives back projections from other pyramidal cells in addition to direct afferences from lateral and medial entorhinal cortices, and indirect afferences from dentate gyrus (DG) via mossy fibers (MF), as well as various projections from inhibitory interneurons that populate this region. A rich connectivity with highly modifiable synapses under the influence of inhibitory controls suggests a capacity for configural association of mnesic information (Morris et al. 2003; Lynch 2004). Various computational hypotheses support the multiple functions of the CA3 area in mnesic phenomena (for reviews, see Kesner 2007; Rolls 2007, 2010). Within the CA3 hippocampal area, MF-CA3 synapses present surprising features such as the highest concentration of vesicular zinc in the CNS. Vesicular zinc, co-localized with glutamate in synaptic vesicles (Frederickson 1989), is considered as an atypical neurotransmitter but also presents specificities not found in classic neurotransmitters. First of all, zinc can modulate the activity of NMDA receptors. Contrary to what has long been a credo, NMDARs are actually present at the MF postsynaptic element allowing coexistence of a presynaptic NMDA-independent form of long-term potentiation (LTP) with a postsynaptic NMDA-dependent LTP (Kwon and Castillo 2008). Experimentally, zinc can be co-released with glutamate in a calcium-dependent way via a simple stimulation (Quinta-Ferreira et al. 2004) or by multiple stimulations (Assaf and Chung 1984). Second, a specific metabotropic receptor for zinc (ZnR) has also been discovered (Besser et al. 2009), which allows zinc to act as a neurotransmitter. Third, zinc can also penetrate into the postsynaptic element through glutamate ionotropic receptors (NMDARs, AMPARs, and KARs) (Sensi et al. 1999)

\footnotetext{
${ }^{4}$ Corresponding author

E-mail lassalle@cict.fr

Article is online at http://www.learnmem.org/cgi/doi/10.1101//m.029017.112.
}

and VDCC receptors (Weiss and Sensi 2000). Translocation of zinc in the postsynaptic element results in the induction of LTP through molecular cascades involved in memory consolidation (Lu et al. 2000; Li et al. 2001a,b). Zinc can also act on intracellular calcium concentration. This "cross-talk" between zinc and calcium suggests a competition between these two signaling ions as illustrated by Takeda et al. (2007). Negative modulation could be linked to plasticity (LTP and LTD) but also play a neuroprotective function in case of MF overstimulation (Bordi and Ugolini 1999). Therefore, concomitant release of zinc and glutamate by MF could result from a wide spectrum of stimulations and consequently match various patterns of DG granular cell activity. Previous studies from our group have shown that Diethyldithiocarbamate (DEDTC), a presynaptic zinc chelator which is supposed to block MF activity in the CA3 region of the dorsal hippocampus, might have different effects on the consolidation of spatial learning in the Morris water maze (MWM) task, according to distributed vs. massed learning practices. DEDTC that can cross membranes and chelate zinc in synaptic vesicles and calcium tetraacetic ethylenediamine acid (CaEDTA), which has an extrasynaptic effect and chelates zinc only after release in the synaptic cleft, were injected either before every session of acquisition, with an expected effect on both acquisition and consolidation (Lassalle et al. 2000; Daumas et al. 2004; Florian and Roullet 2004), or after every session of acquisition, with an expected effect only on consolidation. Injection of DEDTC before learning blocked acquisition of the spatial component of the task in the MWM with distributed learning practice, while injection just after the learning session did not impair consolidation (Lassalle et al. 2000). However, use of a massed procedure in MWM allowed Florian and Roullet (2004) to show an action of DEDTC on spatial reference memory consolidation. In these two studies, capture of vesicular zinc by DEDTC entailed a strong impairment of spatial memory, while chelation of zinc once released by CaEDTA had no effect. Comparable results obtained in the spatial open-field by Stupien et al. (2003) showed that dysfunctioning of the CA3 area induced by inactivation of MF by DEDTC in C57Bl/6J mice disrupted both acquisition and consolidation of the spatial arrangement of a set of objects, 
while it did not disrupt reaction to a new object, which is a hippocampal-independent function (Wan et al. 1999; Albasser et al. 2010). In this set of experiments, lack of effects of CaEDTA questions the real role of zinc and suggests that chelation of vesicular zinc by DEDTC would prevent co-release of both zinc and glutamate. Effects of DEDTC could thus only result from side effects of glutamate release blocking. However, Daumas et al. (2004), using contextual fear conditioning (CFC) with a single training session, with two trials spaced out by $2 \mathrm{~min}$, brought conflicting results. With this rather massed training procedure, DEDTC impaired both acquisition and consolidation, which could appear as a confirmation of results obtained in MWM with massed practice. But, unexpectedly, this study showed that CaEDTA also impaired acquisition and consolidation, while a control chelator, zinc tetraacetic ethylenediamine acid (ZnEDTA), had no effect. This study showed for the first time in vivo that MF vesicular zinc released in the synaptic cleft is clearly involved in acquisition and consolidation of CFC. Zinc could thus play a direct role in this type of learning, contrary to spatial or to object location memory.

Therefore, we postulated that effects of glutamate on NMDARs located on postsynaptic elements of MF (MF-CA3), of temporo-ammonic pathway (TA-CA3), and of associative recurrent collaterals (ARCs) are sufficient to allow consolidation of spatial learning but not for the optimal consolidation of contextual learning. Indeed, in this kind of learning, direct action of zinc would be necessary. We thus expected that in spatial learning, chelation of zinc once released will be ineffective, while blocking NMDARs in the CA3 area will be enough to impair memory consolidation. On the other hand, in CFC, blocking NMDARs associated with chelation of zinc once released would be necessary to impair consolidation. To assess this hypothesis, microinjections of the NMDAR antagonist D-2-amino-5-phosphonopentanoate (AP5) alone or in association with the extracellular zinc chelator CaEDTA were done in the CA3 area after learning MWM and CFC with massed practice.

Inbred C57Bl/6J male mice, 9-12 wk old, were implanted with guide cannulae in the dorsal CA3 area as previously described (Daumas et al. 2004), then randomly allotted to an experimental group and subsequently received the same drug through the whole experimental procedure. After a week of recovery, mice underwent spatial learning with massed practice in the MWM then CFC. This testing order was chosen so that the less stressful learning task was performed first with the aim to minimize order effects. The MWM training procedure started with a familiarization session as used by Lassalle et al. (2008) except that the visible platform was moved to a different location for each familiarization trial. Massed learning with the submerged platform was realized $24 \mathrm{~h}$ later. Mice were given four sessions of three consecutive trials with a 15-20-min ISI. Total duration of learning procedure was limited to $90 \mathrm{~min}$. Twenty-four hours after learning, mice were submitted to a 60 -sec spatial test. Data collection was performed using Ethovision 2.3 (Noldus). During learning sessions, latencies to reach the platform were recorded. During the test, numbers of annuli crossings were analyzed. Statistics were performed with Systat $10.2 ; \alpha$ levels were set at $P<0.05$. Learning performances were analyzed using one factor repeated measures ANOVA. For spatial bias during recall, a repeated measures ANOVA was used to compare annuli crossings. Then, for each treatment, repeated measures ANOVA analyzed variation of annuli crossings. When significant changes in crossings had been detected, Fisher's LSD post-hoc test was used to determine the most frequently crossed annulus.

CFC, carried out $4 \mathrm{~d}$ after MWM, consisted of a single learning session with two trials as described by Daumas et al. (2004). Memory of CFC was measured $24 \mathrm{~h}$ later in the same experimental conditions, followed $2 \mathrm{~h}$ later by assessment of elementary sound- shock association in a modified context. Freezing was used to evaluate fear memory (Blanchard and Blanchard 1969). Freezing occurrences were recorded every $5 \mathrm{sec}$ according to the method of instantaneous sampling at fixed time intervals (Martin and Bateson 1986). Freezing data ( $p$ ) expressed as frequency of immobility episodes were transformed as $Q=\arcsin (\sqrt{ } p / 100)$ then processed by one factor (treatment) ANOVA. Post-hoc comparisons were made using Fisher's LSD tests.

Immediately after every learning session of MWM and CFC, mice received similar $0.25-\mu \mathrm{L}$ bilateral infusions of ZnEDTA (200 $\mathrm{mM})$, AP5 (3.04 mM), or a mixture of AP5 and CaEDTA or AP5 and ZnEDTA in the CA3 area, as described by Daumas et al. (2004), according to their experimental group.

ZnEDTA is a chelator of divalent ions saturated with zinc. CaEDTA, a chelator of divalent ions saturated with calcium, cannot cross membranes which makes it an exclusively extracellular chelator unable to change intracellular zinc homeostasis. CaEDTA was chosen to trap specifically free zinc and zinc released by MF. Zinc affinities of CaEDTA and ZnEDTA are very high $\left(K_{\mathrm{d}}=\right.$ $10^{-16.4} \mathrm{M}$ and $K_{\mathrm{d}}=0^{-15} \mathrm{M}$, respectively), whereas affinities for calcium or magnesium are very low. Consequently, CaEDTA chelates zinc without chelating calcium or magnesium while ZnEDTA chelates none, and can consequently serve as control.

AP5, a competitive antagonist of NMDARs, binds specifically on NMDARs, so preventing any connection of glutamate. The time window of CaEDTA and AP5 is estimated to be $\sim 1 \mathrm{~h}$ (www. drugs.com/ppa/edetate-calcium-disodium-calcium-edta.html).

At the end of behavioral tests, mice were euthanized with pentobarbital ( $150 \mathrm{mg} / \mathrm{kg}$, i.p., cEVA), and their brains processed for histology (Fig. 1; see also Daumas et al. 2004). Subjects with misplaced cannulae and/or injections were excluded from analyses, leading to groups of: ZnEDTA, $n=15$; AP5, $n=11$; ZnEDTA + AP5, $n=14$; and CaEDTA + AP5, $n=10$.

As can be appreciated from Figure 2A, when mice are exposed to a massed learning procedure, they gradually improve their performance. Mean escape latencies decreased significantly over trials in all groups $\left(F_{(3,138)}=12.077, P<0.001\right)$, with no significant variation between groups $\left(F_{(3,46)}=0.345, P=0.793\right)$. Therefore, before receiving treatment, all mice efficiently used distal visual cues and showed comparable learning profiles.

After the last training trial, animals were injected with drug depending on their experimental group, and spatial memory was assessed $24 \mathrm{~h}$ later. During the memory test, if mice are

A

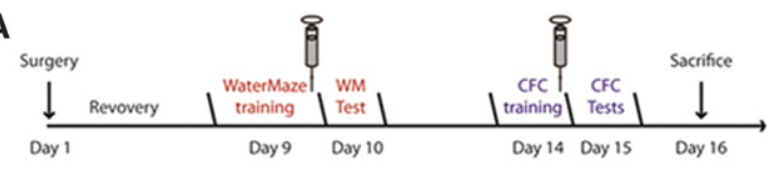

B

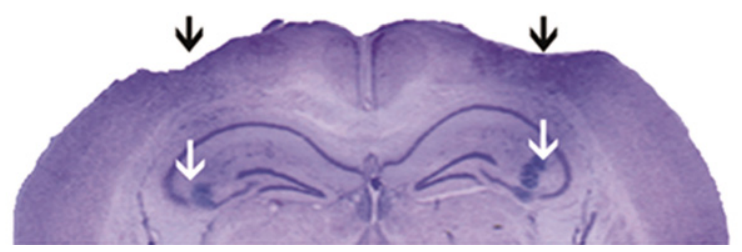

Figure 1. (A) Timeline of the experimental design from surgery to sacrifice of the animals for histology. Note that each behavioral procedure consists of a day training followed by memory test on the consecutive day. (WM) Water maze, (CFC) contextual fear conditioning. (B) Photograph of a frontal section of a mouse dorsal hippocampus stained with thionin. Injection sites can be seen at the level of the CA3 area on both hippocampi (white arrows). Black arrows indicate the position of guide cannulae. 

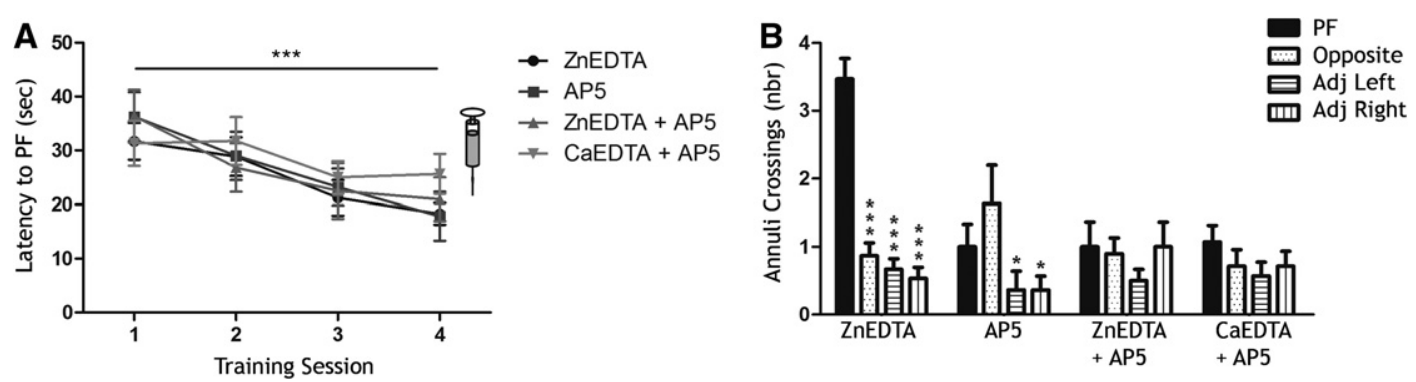

Figure 2. MWM task. $(A)$ Learning performance: mean latency to platform for the different groups over the four massed learning sessions in the MWM. (B) Test of spatial bias: effects of four treatments (ZnEDTA, AP5, ZnEDTA + AP5, CaEDTA + AP5) on the average number of annuli crossings during the recall test at 24 h. (PF) Platform location learned. Results are presented as mean \pm SEM. $\left(^{*}\right) P<0.05,(* * *) P<0.001$.

remembering the previous learning correctly, they should spend more time around the platform location and therefore present a higher number of targeted annulus crossings in comparison with the three other possible positions of it. As shown in Figure 2B only control animals focused their research on the previously learned location $(P<0.001)$. None of the treated groups appropriately retrieved the correct platform location. A significant variation of search profiles between groups appeared $\left(F_{(3,138)}=\right.$ 12.307, $P<0.001)$, with a significant treatment $\times$ annulus crossings interaction $\left(F_{(9,138)}=4661, P<0.001\right)$. Repeated measures ANOVAs performed within each group revealed a heterogeneity in patterns of annuli crossing for groups ZnEDTA $\left(F_{(3,42)}=\right.$ 25.846, $P<0.001)$ and AP5 $\left(F_{(3,30)}=3.805, P=0.020\right)$, while groups CaEDTA + AP5 and ZnEDTA + AP5 showed no such heterogeneity $\left(F_{(3,39)}=1.491, P=0.232\right.$ and $F_{(3,27)}=0.656, P=$ 0.586). Blocking glutamate binding on NMDARs by AP5 clearly disrupted retention of goal learning. Curiously, the AP5-alone treated group presented a peculiar profile. AP5 mice that showed no better recall of the location of the platform than the other treatment groups (AP5 + CaEDTA and AP5 + ZnEDTA) tended to always go back to the release point (opposite to PF location). They showed preferential crossings of the Opposite annulus compared to Adjacent left $(P=0.036)$ and Adjacent right annuli $(P=$ $0.029)$. No differences appeared between search profiles of CaEDTA + AP5 and ZnEDTA + AP5 groups. Combination of extracellular zinc chelator CaEDTA with AP5 provided no additional effect compared to the combination of ZnEDTA with AP5, therefore confirming results from Lassalle et al. (2000) with distributed learning, as well as from Florian and Roullet (2004) with massed learning, about the lack of effect of CaEDTA alone.

Altogether, it can be concluded that the NMDARs antagonist (AP5) caused impaired memory consolidation in MWM, whereas the extracellular zinc chelator (CaEDTA) had no effect.

After a 4-d resting period, mice were submitted to contextual fear conditioning (CFC) before being treated with the drug of their experimental group. During conditioning, all groups show no freezing behavior before the first shock, and a progressive increase of it after the shocks $\left(F_{(10,440)}=28.109, P<0.001\right.$ ) (data not shown).

Twenty-four hours after conditioning and treatment, contextual fear memory was first assessed (Fig. 3A). Although context reexposure in the ZnEDTA control group resulted in slightly lower freezing levels than usually observed in our studies, possibly resulting from previous exposure to MWM learning, rates of contextual freezing showed, nevertheless, a significant variation due to treatments $\left(F_{(3,45)}=9.309, P<0.001, R^{2}=0.384\right)$. Indeed, while the rate of freezing was $54.6 \%$ in the ZnEDTA control group, it was $27.9 \%$ in AP5, $27.4 \%$ in ZnEDTA + AP5, and $17.2 \%$ in the CaEDTA + AP5 group. Fisher's post-hoc tests confirmed significant differences of freezing rates between the ZnEDTA control group and AP5 $(P=0.003)$, ZnEDTA + AP5 $(P=0.002)$, and CaEDTA + AP5 $(P<0.001)$ groups, respectively. Although no significant difference appeared between groups AP5 and ZnEDTA + AP5 $(P=0.580)$, confirming the lack of specific effect of ZnEDTA alone, Fisher's tests showed a significantly greater decrease of freezing rates for the CaEDTA + AP5 compared to the AP5 groups $(P=$ 0.032).

Hippocampal-independent fear memory was then tested (Fig. 3B). As shown in Figure 3B, all groups express very high rates of freezing, $\sim 80 \%$, during sound memory tests, clearly demonstrating that CA3-hippocampal injections did not disturb the elemental sound-shock association $\left(F_{(3,44)}=0.488, P=0.692\right)$.

Therefore AP5 impaired memory consolidation of CFC while a mixture of both AP5 and CaEDTA showed a cumulative effect.

This study analyzed cumulative roles of CA3 zinc and glutamate in the consolidation stage of two forms of hippocampaldependent memories acquired under massed learning procedures. Microinjections of AP5 in CA3 aimed at blocking NMDARs and thus postsynaptic action of glutamate at the CA3 synapses. Coinjections of CaEDTA allowed additional chelation of MF zinc without impacting glutamate release. ZnEDTA appeared to be a good control.

In the MWM, AP5 impaired memory consolidation whereas CaEDTA caused no additional effect. It can therefore be concluded there is a lack of effect of MF zinc chelation on the consolidation of spatial learning, while action of glutamate at the three synapses TA-CA3, MF-CA3, and ARCs is mandatory. On the other hand, in CFC a mixture of both AP5 and CaEDTA resulted in cumulative impairments of memory consolidation. As expected, they had no effect on memory of cue conditioning. These results confirm that consolidation of spatial and contextual memories relies on at least partially different mechanisms. However, these results are at variance with those of Fellini et al. (2009) that found no role for NMDARs in water-maze memory consolidation, using a similar
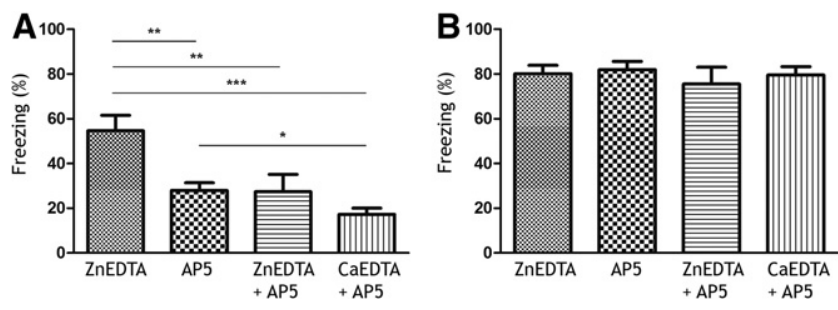

Figure 3. Effects of the four treatments (ZnEDTA, AP5, ZnEDTA + AP5 and CaEDTA + AP5) administered immediately after the conditioning and measured $24 \mathrm{~h}$ later, during the test to the context $(A)$ and $26 \mathrm{~h}$ later during the test to the sound in the modified context $(B)$. Results are presented as mean \pm SEM. $\left({ }^{*}\right) P<0.05,\left({ }^{* *}\right) P<0.01,\left({ }^{* * *}\right) P<0.001$. 
massed procedure. This discrepancy can be explained since, in our study, during familiarization the platform was moved to a different location for each trial, whereas in the Fellini et al. (2009) study the platform remained at the same place during the whole procedure. It has been shown that using the same location for familiarization and learning results in a pre-exposure effect that contributes to the formation of a spatial representation that remains valid during the learning phase. For example, Rudy et al. (2004) have developed the concept of context pre-exposure facilitation effect (CPFE), demonstrating that when rats were pre-exposed to the conditioning context in CFC, inactivation of amygdala following conditioning was of no consequence for consolidating the memory of context because the representation was already established in the hippocampus. Similarly, Roesler et al. (1998) showed that pre-exposure of rats to the inhibitory avoidance box $24 \mathrm{~h}$ before training prevented the amnestic effect of AP5 hippocampal post-training infusion on NMDARs. Therefore, pre-exposure of mice to the spatial learning configuration during familiarization is likely to explain the disengagement of NMDARs during consolidation of spatial memory observed by Fellini et al. (2009) in the MWM.

Direct comparison of MWM and CFC under massed learning procedures reconciles seemingly contradictory results from our group about MF-CA3 pathway involvement in the consolidation of spatial learning in MWM, critical with massed practice (Florian and Roullet 2004) while optional with distributed practice (Lassalle et al. 2000). The importance of training procedure has been raised by Silva's group showing that mice with a partial knockout of the cAMP responsive-element binding (CREB KO) expressed almost normal long-term memories (contextual and spatial) following distributed learning practice, whereas they were severely disrupted with massed learning (Kogan et al. 1996). Therefore, by analogy, we assume that differences in memory consolidation efficiency could rely on training procedures. When MFs are selectively blocked, consolidation remains nevertheless possible in MWM with learning sessions distributed over several days. But, above all, our results strengthen previous conclusions about a specific role for zinc released into the MF-CA3 synaptic cleft on CFC consolidation (Daumas et al. 2004). Direct comparison between CFC and MWM with massed procedure shows, beyond doubt, that the action of glutamate at the three CA3 synapses is necessary and sufficient for the consolidation of spatial learning; MF-CA3 released zinc playing no direct role in this case. On the other hand, both vesicular glutamate and zinc are mandatory and exert cumulative effects on CFC memory consolidation, suggesting involvement of two complementary mechanisms in contextual learning with a strong emotional component.

\section{Acknowledgments}

This work was supported by CNRS and Université de Toulouse. We thank the ABC facility and ANEXPLO for housing mice.

\section{References}

Albasser MM, Poirier GL, Aggleton JP. 2010. Qualitatively different modes of perirhinal-hippocampal engagement when rats explore novel vs. familiar objects as revealed by c-Fos imaging. Eur J Neurosci 31: $134-147$.

Amaral DG, Witter MP. 1995. Hippocampal formation. In The rat nervous system (ed. Paxinos G), pp. 443-493. Academic Press, San Diego, CA.

Assaf SY, Chung SH. 1984. Release of endogenous $\mathrm{Zn}^{2+}$ from brain tissue during activity. Nature 308: 734-736.

Besser L, Chorin E, Sekler I, Silverman WF, Atkin S, Russell JT, Hershfinkel M. 2009. Synaptically released zinc triggers metabotropic signaling via a zinc-sensing receptor in the hippocampus. J Neurosci 29: $2890-2901$.

Blanchard RJ, Blanchard DC. 1969. Crouching as an index of fear. J Comp Physiol Psychol 67: 370-375.
Bordi F, Ugolini A. 1999. Group I metabotropic glutamate receptors: Implications for brain diseases. Prog Neurobiol 59: 55-79.

Daumas S, Halley H, Lassalle JM. 2004. Disruption of hippocampal CA3 network: Effects on episodic-like memory processing in C57BL/6J mice. Eur J Neurosci 20: 597-600.

Fellini L, Florian C, Courtey J, Roullet P. 2009. Pharmacological intervention of hippocampal CA3 NMDA receptors impairs acquisition and long-term memory retrieval of spatial pattern completion task. Learn Mem 16: 387-394.

Florian C, Roullet P. 2004. Hippocampal CA3-region is crucial for acquisition and memory consolidation in Morris water maze task in mice. Behav Brain Res 154: $365-374$.

Frederickson CJ. 1989. Neurobiology of zinc and zinc-containing neurons. Int Rev Neurobiol 31: 145-238.

Kesner RP. 2007. Behavioral functions of the CA3 subregion of the hippocampus. Learn Mem 14: 771-781.

Kogan JH, Frankland PW, Blendy JA, Coblentz J, Marowitz Z, Schutz G, Silva AJ. 1996. Spaced training induces normal long-term memory in CREB mutant mice. Curr Biol 7: 1-11.

Kwon HB, Castillo PE. 2008. Long-term potentiation selectively expressed by NMDA receptors at hippocampal mossy fiber synapses. Neuron 57: $108-120$.

Lassalle JM, Bataille T, Halley H. 2000. Reversible inactivation of the hippocampal mossy fiber synapses in mice impairs spatial learning, but neither consolidation nor memory retrieval, in the Morris navigation task. Neurobiol Learn Mem 73: 243-257.

Lassalle JM, Halley H, Daumas S, Verret L, Francés B. 2008. Effects of the genetic background on cognitive performances of Tg2576 mice. Behav Brain Res 191: 104-110.

Li Y, Hough CJ, Frederickson CJ, Sarvey JM. 2001a. Induction of mossy fiber $\rightarrow$ Ca3 long-term potentiation requires translocation of synaptically released $\mathrm{Zn}^{2+}$. J Neurosci 21: 8015-8025.

Li Y, Hough CJ, Suh SW, Sarvey JM, Frederickson CJ. 2001b. Rapid translocation of $\mathrm{Zn}^{2+}$ from presynaptic terminals into postsynaptic hippocampal neurons after physiological stimulation. J Neurophysiol 86: $2597-2604$.

Lu YM, Taverna FA, Tu R, Ackerley CA, Wang YT, Roder J. 2000. Endogenous $\mathrm{Zn}^{2+}$ is required for the induction of long-term potentiation at rat hippocampal mossy fiber-CA3 synapses. Synapse 38: 187-197.

Lynch MA. 2004. Long-term potentiation and memory. Physiol Rev 84: $87-136$.

Martin P, Bateson P. 1986. Measuring behaviour: An introductory guide. Cambridge University Press, Cambridge, UK.

Morris RG, Moser EI, Riedel G, Martin SJ, Sandin J, Day M, O’Carroll C. 2003. Elements of a neurobiological theory of the hippocampus: The role of activity-dependent synaptic plasticity in memory. Philos Trans $R$ Soc Lond B Biol Sci 358: 773-786.

Quinta-Ferreira ME, Matias CM, Arif M, Dionisio JC. 2004. Measurement of presynaptic zinc changes in hippocampal mossy fibers. Brain Res 1026: $1-10$

Roesler R, Vianna M, Sant'Anna M, Kuyen CR, Kruel AVS, Quevedo J, Cardoso Ferreira MB. 1998. Intrahippocampal infusion of the NMDA receptor antagonist AP5 impairs retention of an inhibitory avoidance task: Protection from impairment by pretraining or preexposure to the task apparatus. Neurobiol Learn Mem 69: 87-91.

Rolls ET. 2007. An attractor network in the hippocampus: Theory and neurophysiology. Learn Mem 14: 714-731.

Rolls ET. 2010. A computational theory of episodic memory formation in the hippocampus. Behav Brain Res 215: 180-196.

Rudy JW, Huff NC, Matus-Amat P. 2004. Understanding contextual fear conditioning: Insights from a two-process model. Neurosci Biobehav Rev 28: 675-685.

Sensi SL, Yin HZ, Carriedo SG, Rao SS, Weiss JH. 1999. Preferential Zn ${ }^{2+}$ influx through $\mathrm{Ca}^{2+}$-permeable AMPA/kainate channels triggers prolonged mitochondrial superoxide production. Proc Natl Acad Sci 96: $2414-2419$.

Stupien G, Florian C, Roullet P. 2003. Involvement of the hippocampal CA3-region in acquisition and in memory consolidation of spatial but not in object information in mice. Neurobiol Learn Mem 80: $32-41$.

Takeda A, Fuke S, Minami A, Oku N. 2007. Role of zinc influx via AMPA/ kainate receptor activation in metabotropic glutamate receptor-mediated calcium release. J Neurosci Res 85: 1310-1317.

Wan H, Aggleton JP, Brown MW. 1999. Different contributions of the hippocampus and perirhinal cortex to recognition memory. J Neurosci 19: $1142-1148$.

Weiss JH, Sensi SL. 2000. $\mathrm{Ca}^{2+}-\mathrm{Zn}^{2+}$ permeable AMPA or kainate receptors: Possible key factors in selective neurodegeneration. Trends Neurosci 23: $365-371$.

Received October 15, 2012; accepted in revised form April 26, 2013. 


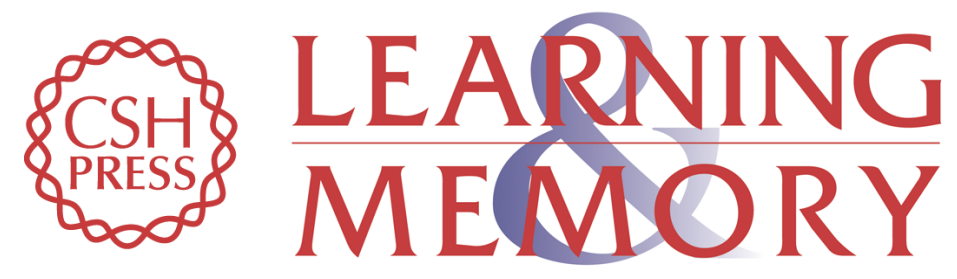

\section{Differential needs of zinc in the CA3 area of dorsal hippocampus for the consolidation of contextual fear and spatial memories}

Johnatan Ceccom, Emilie Bouhsira, Hélène Halley, et al.

Learn. Mem. 2013, 20:

Access the most recent version at doi:10.1101/lm.029017.112

References This article cites 29 articles, 7 of which can be accessed free at: http://learnmem.cshlp.org/content/20/7/348.full.html\#ref-list-1

Creative This article is distributed exclusively by Cold Spring Harbor Laboratory Press for the Commons License first 12 months after the full-issue publication date (see

http://learnmem.cshlp.org/site/misc/terms.xhtml). After 12 months, it is available under a Creative Commons License (Attribution-NonCommercial 3.0 Unported), as described at http://creativecommons.org/licenses/by-nc/3.0/.

Email Alerting Receive free email alerts when new articles cite this article - sign up in the box at the Service top right corner of the article or click here. 